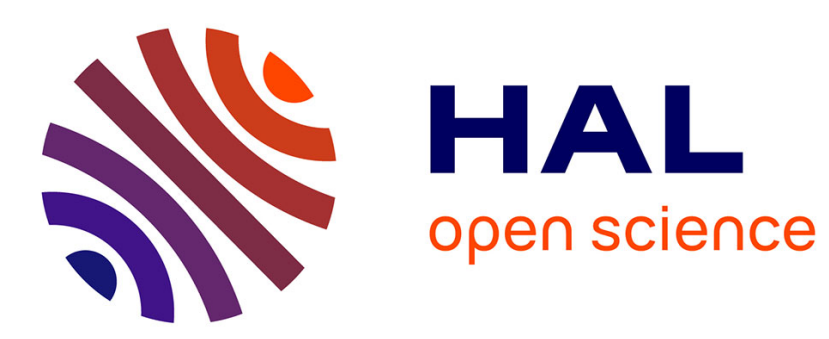

\title{
The neurotoxicology of uranium
}

Céline Dinocourt, Marie Legrand, Isabelle Dublineau, Philippe Lestaevel

\section{To cite this version:}

Céline Dinocourt, Marie Legrand, Isabelle Dublineau, Philippe Lestaevel. The neurotoxicology of uranium. Toxicology, 2015, 337, pp.58-71. 10.1016/j.tox.2015.08.004 . hal-02572592

\section{HAL Id: hal-02572592 \\ https://hal.science/hal-02572592}

Submitted on 22 Oct 2021

HAL is a multi-disciplinary open access archive for the deposit and dissemination of scientific research documents, whether they are published or not. The documents may come from teaching and research institutions in France or abroad, or from public or private research centers.
L'archive ouverte pluridisciplinaire HAL, est destinée au dépôt et à la diffusion de documents scientifiques de niveau recherche, publiés ou non, émanant des établissements d'enseignement et de recherche français ou étrangers, des laboratoires publics ou privés. 


\title{
The neurotoxicology of uranium
}

\author{
Céline Dinocourt ${ }^{1}$, Marie Legrand, Isabelle Dublineau ${ }^{2}$, Philippe Lestaevel ${ }^{*}$ \\ Institut de Radioprotection et de Sûreté Nucléaire (IRSN), Pôle de la Radioprotection de l'Homme, Service de Radiobiologie et d'Epidémiologie, Laboratoire de \\ Radiotoxicologie Expérimentale, BP 17, F-92262 Fontenay-aux-Roses, France
}

\begin{abstract}
The brain is a target of environmental toxic pollutants that impair cerebral functions. Uranium is present in the environment as a result of natural deposits and release by human applications. The first part of this review describes the passage of uranium into the brain, and its effects on neurological functions and cognitive abilities. Very few human studies have looked at its cognitive effects. Experimental studies show that after exposure, uranium can reach the brain and lead to neurobehavioral impairments, including increased locomotor activity, perturbation of the sleep-wake cycle, decreased memory, and increased anxiety. The mechanisms underlying these neurobehavioral disturbances are not clearly understood. It is evident that there must be more than one toxic mechanism and that it might include different targets in the brain. In the second part, we therefore review the principal mechanisms that have been investigated in experimental models: imbalance of the anti/pro-oxidant system and neurochemical and neurophysiological pathways. Uranium effects are clearly specific according to brain area, dose, and time. Nonetheless, this review demonstrates the paucity of data about its effects on developmental processes and the need for more attention to the consequences of exposure during development.
\end{abstract}

\footnotetext{
* Corresponding author. Fax: +33158358467.

E-mail addresses: celine.dinocourt@irsn.fr (C. Dinocourt), marie.legrand@irsn.fr (M. Legrand), isabelle.dublineau@irsn.fr (I. Dublineau), philippe.lestaevel@irsn.fr (P. Lestaevel).

1 Present address: IRSN, Direction de la Stratégie du Développement et des Partenariats, Service Programmes et Stratégies Scientifiques.

2 Present address: IRSN, Pôle de la Radioprotection de l'Homme.
} 


\section{Introduction}

An extensive literature has already documented the deleterious effects of environmental toxic pollutants such as metals on the brain and nervous system (Liu and Lewis, 2014). Uranium is the heaviest naturally occurring metallic element and is found in the Earth's crust. Due to its presence in soil, rocks, surface and underground water, air, plants, and animals, it occurs in trace amounts in many foods and in drinking water. Its release into the environment raises questions about its effects on human health (ATSDR (Agency for Toxic Substances and Disease Registry), 2013). Natural uranium contains three isotopes: uranium-238, uranium235, and uranium-234. An 'enriched' form of uranium, in which the uranium-235 concentration is enhanced, is required to produce energy both in nuclear reactors and nuclear weapons. The remaining uranium mixture (after the enriched uranium is removed) has reduced concentrations of the uranium-235 and uranium-234 isotopes; this is known as depleted uranium. The relatively high availability and low cost of depleted uranium have led to the development of various civilian and military applications (Bleise et al., 2003). Toxicity due to uranium is radiological, because the element emits radiations, and also chemical due to its being a heavy element. Because depleted and natural uranium produces very little radioactivity per mass of uranium, the health effects from exposure of humans and animals to uranium are usually attributed to the chemical properties of uranium.

After exposure to uranium, some target organs of toxicity have been identified, such as kidneys, liver, lungs and brain. It is well known that the uranium toxicity threshold varies also according to the time and the route of its exposure.

Several human populations may be exposed to uranium, notably workers involved in one of the different stages of the nuclear fuel cycle leading to the production of electricity from uranium in nuclear power reactors: exploration, uranium mining, milling, uranium conversion, enrichment, fabrication of nuclear fuel and reprocessing. In addition to these workers, Gulf war and Balkan Veterans were exposed to depleted uranium used in munitions and armors that were extensively used from the 1991 Gulf War (Bleise et al., 2003) as well as populations living in environment affected by depleted uranium-munitions use. Finally, general public may be exposed to uranium in some countries and counties with high natural uranium levels in drinking water (Canu et al., 2011).

For all these reasons, uranium has been the subject of several studies, particularly on its health effects. So, our review discusses the available data published in the last 10 years on uranium effects on cerebral functions. We therefore wrote two parts: the first describes the passage of uranium into the brain and its impact on behavior, while the second focuses on the cellular and molecular mechanisms of action underlying its central effects.

\section{Part I: brain accumulation and behavioral effects}

Uranium is primarily an alpha emitter and represents a radiation hazard only after internal exposure. Uranium enters the human body by ingestion and inhalation of airborne uraniumcontaining dust particles or aerosols. Uranium is absorbed from the intestine or the lungs, enters the bloodstream, and is rapidly deposited in the tissues, predominantly kidneys and bone, or excreted in the urine. Uranium's major adverse effect is renal toxicity after acute exposure (Fukuda et al., 2006), which is more difficult to demonstrate after chronic exposure (Poisson et al., 2014). Concerning the brain, uranium content was measured in whole brain or in specific cerebral structures following different types of exposure: intraperitoneal injection (Lestaevel et al., 2005b), ingestion via drinking water (Bellés et al., 2005; Gilman et al., 1998; Ortega et al., 1989; Paquet et al., 2006), inhalation (Houpert et al., 2007c; Monleau et al., 2005) and following implanted depleted uranium pellets (Pellmar et al., 1999b). A real accumulation of uranium in cerebral structures was not always demonstrated after ingestion, since studies reported comparable uranium quantity in uranium-contaminated animals and uncontaminated animals (Houpert et al., 2005; Lestaevel et al., 2005a, 2009). Nevertheless some cerebral structures, such as striatum, cortex or hippocampus, accumulate more uranium than others (Barber et al., 2005; Paquet et al., 2006). Several studies indicated the absence of a clear dose-dependent accumulation of uranium (Bellés et al., 2005; Dublineau et al., 2014; Gilman et al., 1998; Ortega et al., 1989). Finally, uranium accumulation was clearly observed at long term in rats with implanted depleted uraniumpellets (Fitsanakis et al., 2006; Pellmar et al., 1999a,b). Thus, the issue on the uranium presence in central nervous system is still on the table and deserves further investigations to resolve it. Differential mechanisms of passage have been proposed to explain this cerebral presence of uranium.

\section{The mechanisms of uranium passage into the brain and its localization}

A possible vascular transfer of uranium has been suggested by only a study carried out by Lemercier et al. (2003) showing that uranium did not impair the integrity of the blood-brain barrier (BBB). In vitro, uranium does not induce toxicity on RBE4 cells (Dobson et al., 2006). The mechanism of the blood-brain transfer, however, remains unknown. Uranium may bind with other metals transporters, i.e.transferrin, ferritin or transporter divalent metal type 1 (DMT1), known to be not evenly spread on the brain (Hémadi et al., 2010; Konietzka et al., 2014). In the bone, Basset et al. (2013) suggest that fetuin A is a major protein target for uranium (Basset et al., 2013). Thus uranium could use similar transporters or blood proteins to pass through the brain barrier as demonstrated in other organs. These assumptions have not been confirmed yet and need more investigations with in vitro BBB models.

After inhalation or instillation exposure of rats, uranium is transferred directly from the nasal cavity to the olfactory bulbs, as well as through the bloodstream (Monleau et al., 2005; Tournier et al., 2009). This passage goes via the cerebrospinal fluid along the olfactory nerve (Ibanez et al., 2014).

The next questions to consider are the cellular and subcellular localizations of uranium in the brain. Use of a laser microdissection technique combined with inductively coupled plasma mass spectrometry (LMD ICP-MS) has recently made it possible to show uranium in the pyramidal cell layer of the mouse hippocampus, in brain tissue stained with uranium solution at $100 \mathrm{mg} / \mathrm{L}$ (Sussulini and Becker, 2015). Rouas et al. (2010) also demonstrated in vitro that after exposure at low concentrations, uranium is localized mainly in the nucleus in neuronal (IMR-32) cell lines. At level of the proximal tubule cells of the kidneys, the uptake of uranium is mediated by a sodium-dependent phosphate 


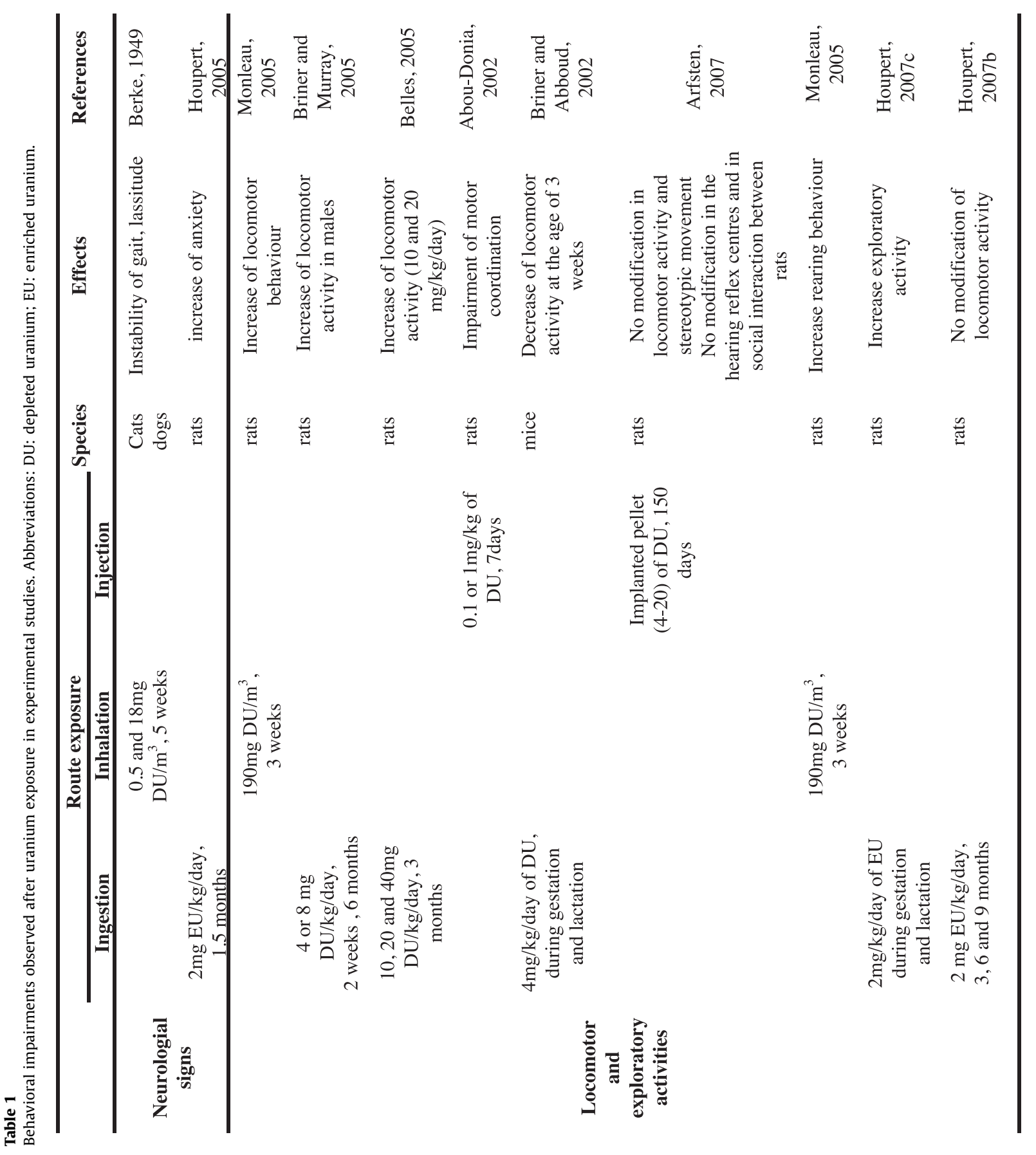




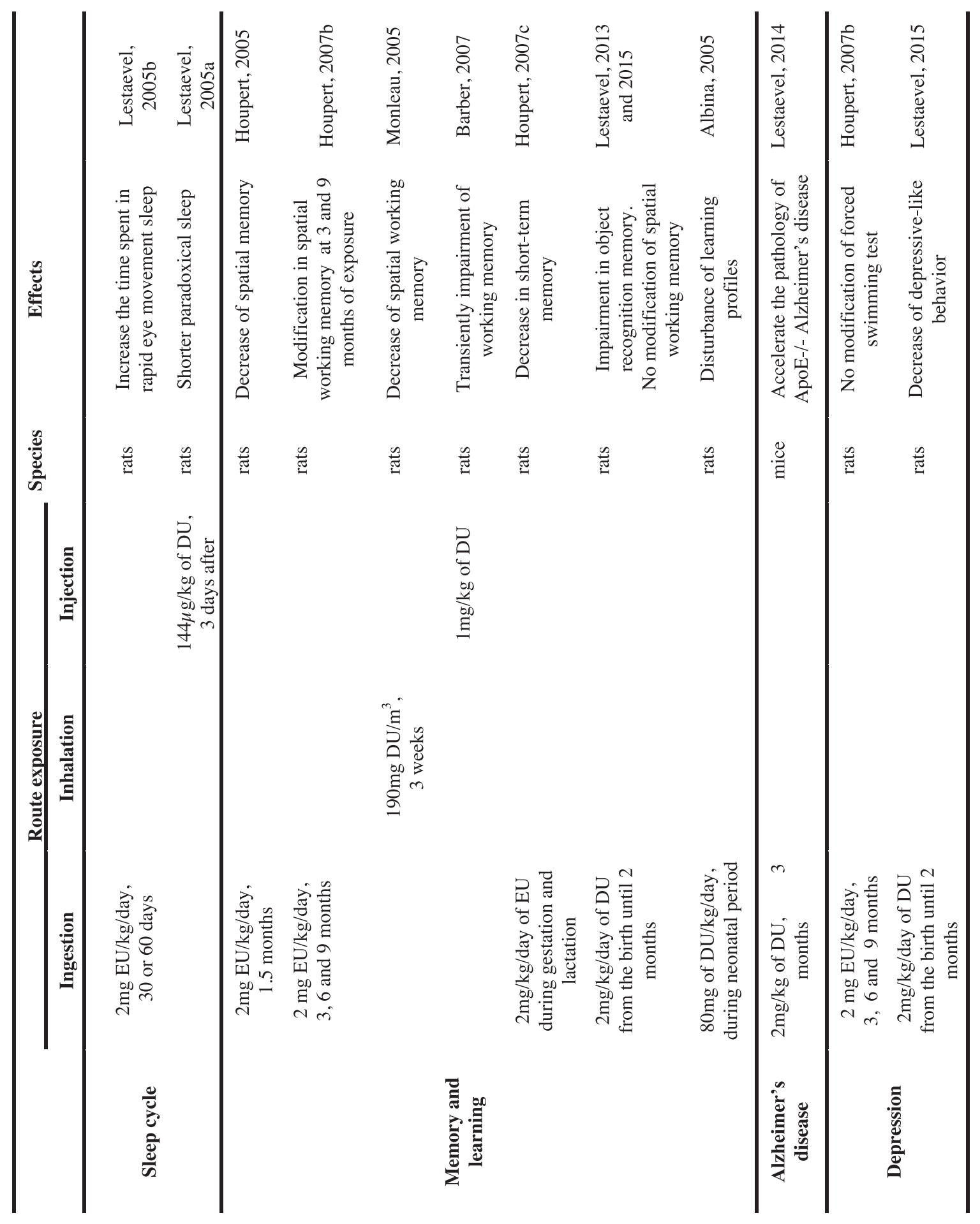


co-transporter system (Muller et al., 2006). These co-transporters are perhaps also implicated at cerebral level. Type III of sodiumphosphate co-transporters are present in the brain and are localized in neurons, astrocytes and endothelial cells (Inden et al., 2013). Nevertheless, the main types of sodium-phosphate cotransporters in the kidneys are type II (subtype IIa and IIb) and are not expressed in brain (Hilfiker et al., 1998). These results raise the question of how uranium penetrates into brain cells and thus open new perspectives for studying the mechanisms of its toxicity.

In conclusion, the studies to underlie the mechanisms of how uranium could enter into the brain are still in progress. After inhalation, uranium is able to bypass the BBB to pass into the brain. It may also cross the BBB without alterations, but the exact mechanisms of this transfer are still unknown.

The next half describes the neurobehavioral disturbances that this passage into the brain causes.

\section{Behavioral effects}

Behavioral effects in humans and in various other animal species have been reported after uranium exposure. Epidemiological surveys of humans do not always make it possible to connect behavioral disorders to specific causal factor, because it is difficult to control all environmental variables. However, certain parameters can be controlled in experimental animal models. Consequently, rodents, in particular, have been used in several types of experiments to study behavioral responses.

\subsection{Epidemiological studies}

Behavioral disturbances have been observed in workers exposed to high concentrations of inhaled uranium. These workers showed signs of depression, apprehension, motor and language disorders (Howland, 1948). In longer-term exposures, epidemiologic studies report contradictory results about deaths from brain tumors and central nervous system cancers in nuclear workers (including miners). Mortality from cancer of the brain and central nervous system was found in excess in the post-55 French cohort of uranium miners (Rage et al., 2015; Vacquier et al., 2011), but there is no evidence of an association with cumulated exposure to radionuclides arising from uranium ore dust. Similarly, no doseresponse trends were found in nuclear fuel workers between brain and central nervous system cancer mortality and cumulated lung dose equivalent used for the evaluation of internal radiation exposure (Boice et al., 2006; Carpenter et al., 1988; Checkoway et al., 1988). No increase of central nervous system cancer was observed in Gulf war veterans (Macfarlane et al., 2003; Storm et al., 2006).

Since the first Gulf war in 1991, symptoms of several veterans remained unexplained (Blanck et al., 1995). The correlation between these symptoms and the depleted uranium exposure was not clearly demonstrated. Monitoring veterans of Gulf War I has shown a reduction in cognitive abilities 7 years after exposure via wounds and penetration of uranium fragments, correlated with uranium concentrations in excreted urine (McDiarmid et al., 2002). However, further studies performed between 12 and 20 years after exposure have not confirmed these observations (McDiarmid et al., 2006, 2013). These cognitive disorders may be correlated to depleted uranium but might also be due to the psychological reactions induced by war. Stress-related health complaints are a common sequel and may add to the confusion about possible health consequences. Moreover, not all of the embedded fragments contained depleted uranium. Indeed, some fragments were primarily composed of copper, lead, iron, and zinc, which are known to cause neurological effects (Squibb et al., 2012).
Finally, Goasguen et al. (1982) reported the case of a man aged 50 years with a 6-year history of several neurological disorders, manifested by loss of balance, motor weakness, and limb atrophy. Extensive clinical examinations led to the detection of significant amounts of uranium in his feces. In the absence of any other apparent cause, these neurological deficits were attributed to uranium exposure, from a clipboard that the patient handled daily for three years. No reports about this patient and his subsequent medical monitoring appear to exist.

In conclusion, few scientific studies have directly addressed the health effects of uranium on humans. Larger studies with epidemiologically appropriate sampling and assessment tools need to be conducted on populations living around nuclear plants, for example. This paucity of human studies has led to some animal experimental studies to improve our knowledge of uranium's behavioral effects.

\subsection{Experimental studies on animals exposed to uranium during adulthood}

After exposure to uranium, locomotion, sleep-wake cycle and cognitive functions can be modified (Table 1). Summary of literature examining behavioral responses to uranium exposure in rodents is presented in Table 1 . This overview of available data indicates the dose, the time of exposure and the species.

\subsubsection{Effect on locomotion}

After inhalation of uranium between 0.5 and $18 \mathrm{mg} \mathrm{U} / \mathrm{m} 3$ during several weeks ( $8 \mathrm{~h} /$ day, 5 days/week, during until 5 weeks), neurological signs including gait instability and lassitude have been observed in dogs and cats (Berke and Rothstein, 1949). In rats exposed to $190 \mathrm{mg} \mathrm{U} / \mathrm{m}^{3}$ as depleted uranium dioxide $30 \mathrm{~min} / \mathrm{day}$, 4 days/week for 3 weeks, locomotor and rearing behaviors increased significantly compared with controls on day 1 after the end of the inhalation period, but not on day 5 (Monleau et al., 2005).

Another neurobehavioral study examined the effects of depleted uranium alloy pellets (between 4 and 20 pellets) implanted in the gastrocnemius muscle of male and female adult rats (Arfsten et al., 2007). After 150 days, the authors conducted three tests from the battery of behavioral assessments of toxicity. The first test measured spontaneous locomotor activity and stereotypic movements, the second the integrity of the hearing reflex centers in the brainstem, and the third social interactions between rats. No neurobehavioral perturbations associated with depleted uranium implantation were observed in any of these tests. The authors determined, however, that further studies are needed, with more implants and longer exposure, before any definitive conclusion can be reached about the impact on rat behavior of intramuscularly implanted depleted uranium fragments.

Repeated injections of 0.1 or $1 \mathrm{mg} / \mathrm{kg}$ of uranium for 7 days impaired the motor coordination of rats (Abou-Donia et al., 2002). It is possible that uranium-induced locomotor deficits are linked to an overstimulation of the receptors modulated by excitatory amino acids. Administration of depleted uranium at 4,8 or $10 \mathrm{mg} \mathrm{kg} /$ day to rats via their drinking water for 2 weeks, 3 or 6 months significantly increased locomotor activity in males (Bellés et al., 2005; Briner and Murray, 2005). In the same experimental conditions, female locomotor activity was modified but not significantly (Briner and Murray, 2005). The resistance of females to uranium may be due to a difference in hormonal regulation. These results suggested that the role of the hypothalamo-pituitary axis must be considered in uranium neurotoxicity. 
In summary, locomotor activities are impaired in animals exposed to uranium (Table 1). However, the exact mechanism by which uranium induces these locomotor effects remains to be elucidated. Nitric oxide, uranium replacement of calcium in the electrophysiological system, and the role of motoneurons might all play a role in these impairments.

\subsubsection{Effects on the sleep-wake cycle}

Three days after injection of $144 \mu \mathrm{g}$ of depleted uranium $/ \mathrm{kg}$, a central effect manifested by shorter rapid eye movement (REM) sleep $(-18 \%$ compared with controls) was observed in rats (Lestaevel et al., 2005b). This effect on REM sleep is explained by a decrease of the number and the mean duration of REM sleep episodes. Another study examining the effects of uranium on the sleep cycle found that more time was spent in REM sleep by rats exposed to enriched uranium at $2 \mathrm{mg} / \mathrm{kg} /$ day in mineral water for both 30 and 60 days (Lestaevel et al., 2005a). This increase in REM sleep was due to an increase in the number of REM sleep episodes rather than in episode duration. The finding that these increases in the amount of REM sleep occurred primarily during the daylight period (rats' normal sleeping period) suggests that circadian rhythms were unaffected. The neurophysiological mechanisms underlying REM sleep increases are only very partially understood. A role for the hypothalamo-pituitary axis in sleep regulation has been suggested, notably a role for glucocorticoids in the modulation of REM sleep (Born et al., 1991).

These early neurophysiological perturbations of REM sleep might subsequently induce other neurological effects. This sleep plays a fundamental role in memory processes, and its modification could induce their impairment (Jouvet, 1994).

\subsubsection{Effects on cognitive functions}

Barber et al. (2007) showed that intramuscular injection of $1 \mathrm{mg} / \mathrm{kg}$ of depleted uranium caused rapid, but only transient impairment of working memory in rats. A significant decrease in spatial working memory was also observed on day 6 after the end of prolonged (3-week) inhalation exposure to $190 \mathrm{mg}$ depleted uranium $/ \mathrm{m}^{3}$ (Monleau et al., 2005).

Rats exposed to $4 \%$ enriched uranium at $2 \mathrm{mg} / \mathrm{kg} /$ day for 1.5 months via drinking water have showed significantly decreased spatial working memory and increased anxiety (Houpert et al., 2005). In another study, a test for spatial working memory in a Ymaze was conducted after 3,6 , and 9 months of exposure to enriched uranium (Houpert et al., 2007a). The spatial working memory was decreased after 3 and 9 months of exposure. According to the investigators, these results may indicate that enriched uranium disrupts memory in spatial tasks involving the hippocampus but not in different tasks in which hippocampal functioning is less crucial. In the same experimental conditions, depleted uranium had no significant effect on memory or anxiety (Houpert et al., 2005). An imbalance of reactive oxygen species (ROS) and lipid peroxidation in the entorhinal cortex might explain the different behavioral effects induced by enriched and depleted uranium (Lestaevel et al., 2009).

Finally, the spatial working memory of Apolipoprotein E-Imice exposed to $2 \mathrm{mg}$ of depleted uranium/ $\mathrm{kg} /$ day for 3 months decreased, suggesting that uranium exposure might accelerate the Alzheimer disease (Lestaevel et al., 2014). The behavioral modifications induced by uranium in Apolipoprotein E-/- mice might be, at least in part, linked to modifications of cholesterol in the brain (Lestaevel et al., 2014).

The most probable hypothesis to explain the cognitive effects observed is that uranium exerts a direct effect on one of the cerebral areas where it accumulates. One such cerebral area is the hippocampal region, which plays a pivotal role in spatial learning and memory (Rubaj et al., 2003; Stepanichev et al., 2003). The hippocampus is therefore particularly relevant for considering the neurocognitive disturbances observed with uranium.

In conclusion, whatever the route of exposure, uranium is able to induce impairments in locomotor activities, sleep-wake cycle or memory in animals (Table 1 ). Nevertheless, it is necessary to have a dose range around $\mathrm{mg} / \mathrm{kg}$ to observe these effects. It also appears that enriched uranium induced more behavioral effects than depleted uranium in the same experimental conditions.

\subsection{Effects on animals exposed to uranium during development}

To date, everything we know about the potential neurodevelopmental effects of uranium comes from experimental work on animals. Environmental contaminants can induce and exacerbate the neurotoxic effects when these agents are present during the critical neonatal period of brain development (Eriksson et al., 2010). The immature brain is known to be more susceptible to pollutants than the adult brain. Data about the perinatal and postnatal effects of uranium in rodents are currently sparse, and they have focused on developmental toxicity and fetal development (Domingo 2001; Paternain et al., 1989).

Parental exposure to uranium during gestation and lactation affects behaviors such as environmental responses, learning, activity, exploration, and emotionality. In one study, Briner and Abboud (2002) showed that mice exposed to depleted uranium at a dose of $4 \mathrm{mg} / \mathrm{kg} /$ day during gestation and lactation exposed mothers via drinking water showed $20 \%$ less locomotor activity at the age of 3 weeks than controls. On the contrary, after maternal exposure to enriched uranium at $2 \mathrm{mg} / \mathrm{kg} /$ day during gestation and lactation, the exploratory activity of offspring increased significantly $(+72 \%$ and $+88 \%$ at 5 and 9 months of age, respectively) and the spatial working memory decreased significantly $(-15 \%$ at 2 months of age) (Houpert et al., 2007b). Another study suggested that learning profiles were disturbed in young rats exposed to $80 \mathrm{mg}$ of depleted uranium $/ \mathrm{kg} /$ day during the neonatal period and lactation (Albina et al., 2005). It has been suggested that greater lipid oxidation in the brain of animals exposed during development, correlated with behavioral effects, explains these changes.

Developmental and brain biochemistry changes occur rapidly during the brain growth spurt. For rats, this period is neonatal and occurs during the first 3-4 weeks after birth. Uranium exposure via maternal milk and next drinking water, from birth for 2 months impaired object recognition memory ( $-20 \%)$, anxiety $(+37 \%)$, and depressive-like behavior $(-51 \%)$ but not spatial working memory (Lestaevel et al., 2013, 2015). After 4 months of exposure, the effect on object recognition memory disappeared. These experiments on rats exposed from birth emphasized the ability of the brain to adapt to or compensate for the effects of uranium over time.

These data suggests that uranium induces more behavioral disturbances in animals exposed during cerebral development than in adult. Further studies are necessary to understand how uranium might cause these cerebral dysfunctions.

\section{Conclusion}

In conclusion, evidence that uranium is active in the brain includes its accumulation in cerebral areas and its behavioral effects. Nonetheless, experimental findings about these behavioral effects of uranium are sometimes contradictory, and their interpretation is complex. They can be connected to a large number of cellular and molecular causes. Although we know that neurotransmitters and oxidative stress might play a role, the exact neurobiological basis of uranium impairment of neurobehavioral functions remains unclear. Some of the mechanisms underlying these behavioral effects observed after uranium exposure will be 
discussed in part 2: cellular and molecular mechanisms underlying the effects of uranium.

\section{Part II: cellular and molecular mechanisms underlying the effects of uranium}

As described in part 1, neurological disturbances occur in the brain after exposure to uranium, but the mechanisms by which they happen are still poorly understood. In this part 2, we describe the potential mechanisms underlying these behavioral modifications.

The effects of uraniumchemical toxicity appear similar to those of other heavy metals, including cadmium, lead, and mercury (Tchounwou et al., 2012). Thus, the neurotoxicity in those metals is usually examined by inflammatory and oxidative stress responses, apoptosis and necrosis cell death or neuronal signaling and intracellular signal transduction. In addition, there might well be more than one toxic mechanism for uranium, and they could include different targets (including, for example, DNA binding, transcriptional factors that alter gene expression, and involvement of reactive oxygen species).

Most of the data in the literature come from studies that focused principally on the effects of depleted uranium on adult rodents. Study of the effects on developing animals is just beginning. Thus, the first half of this review will describe pathways investigated in experimental adult models, and the second half, some paths recently explored in developing rodents.

\section{Mechanistic pathways in adult brains}

\subsection{Oxidative stress}

The brain is particularly susceptible to oxidative damage because of its high oxidative metabolism rate, high concentrations of polyunsaturated fatty acids, low to moderate levels of antioxidant enzymes, and high iron level. Oxidative stress due to a reactive oxygen species (ROS) imbalance might therefore be a mechanism of uranium neurotoxicity. The lipid membrane is a preferential target of this ROS-induced oxidative damage, which causes lipid peroxidation. Oxidation of brain lipids after uranium exposure is well documented (Briner and Davis, 2002; Briner and Murray, 2005; Lestaevel et al., 2009; Ghosh et al., 2007; Linares et al., 2007). Correlations between lipid peroxidation in the brain and locomotor activity disturbances have been demonstrated in adult rats and mice after short- (2 weeks) and long-term (6 months) exposure to high concentrations of uranium (Briner and Davis, 2002; Briner and Murray, 2005). Increased lipid peroxidation has been observed in particular the cortex and cerebellum after 3 months of uranium contamination $(10,20$, and $40 \mathrm{mg} / \mathrm{kg} /$ day; Linares et al., 2007) and in the entorhinal cortex after 9 months of uranium contamination ( $2 \mathrm{mg} / \mathrm{kg} / \mathrm{day}$; Lestaevel et al., 2009). However, lipid peroxidation was unaffected in the hippocampus (Linares et al., 2007). These results show that uranium increases lipid peroxidation in specific areas and suggests that cell membranes are damaged by oxidative stress induction

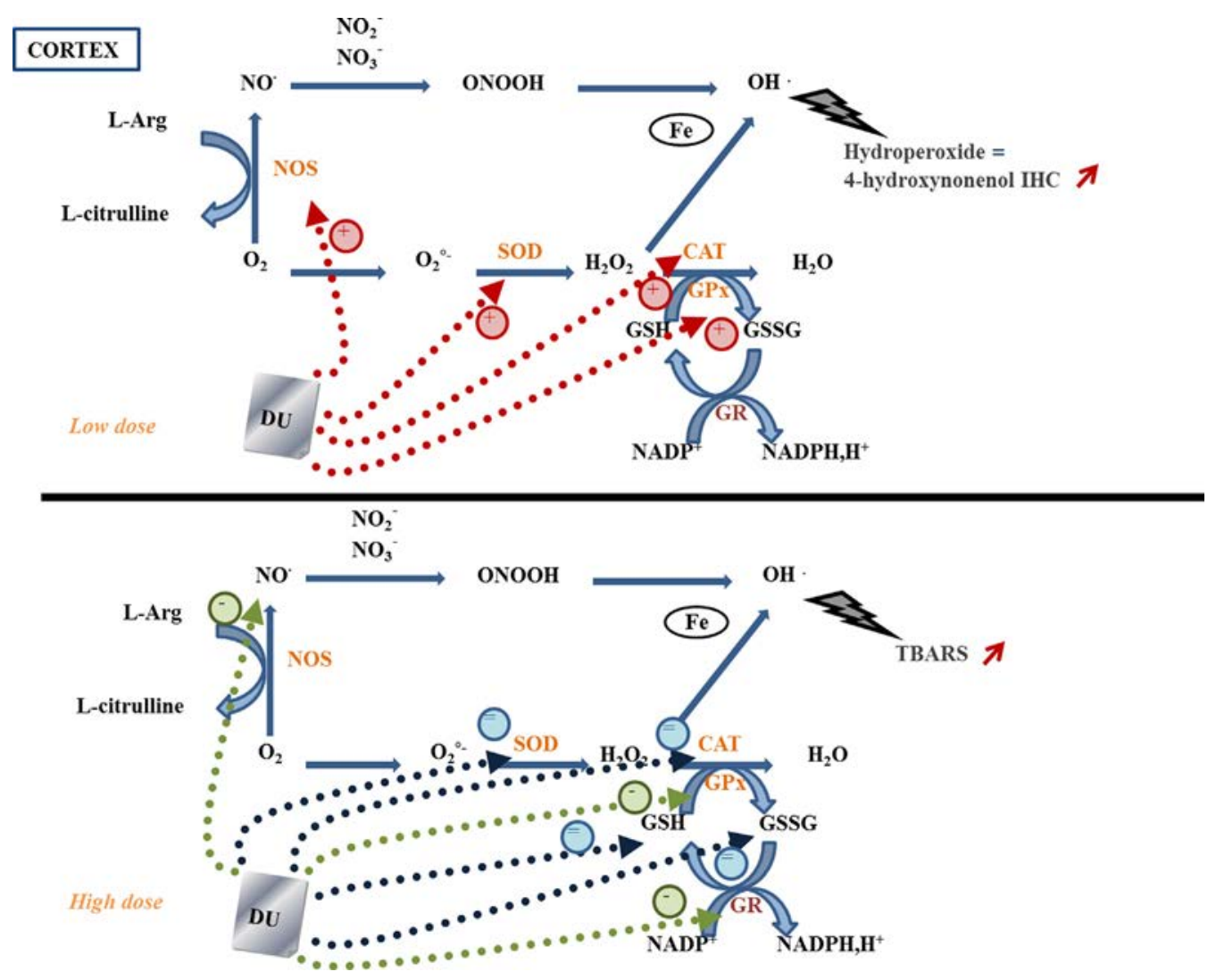

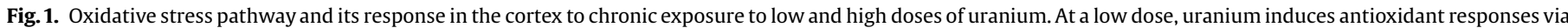

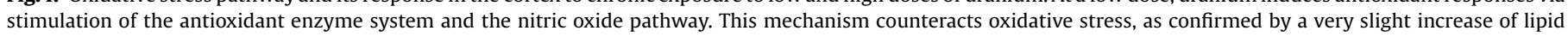

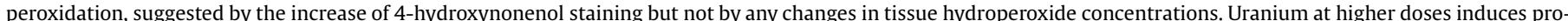

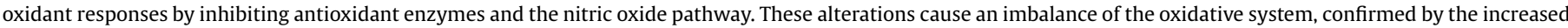

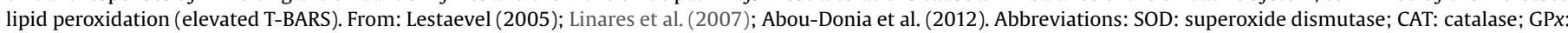

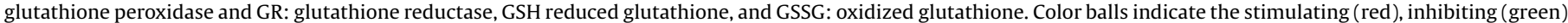

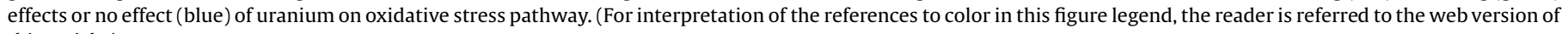
this article.) 
and free radical production. Uranium may thus impair ion conductance, cell membrane fluidity, and other cellular functions in the brain, as observed in other organs. For example, uranium induced-lipid peroxidation could cause mitochondrial membrane damage and significant collapse of mitochondrial membrane potential (Pourahmad et al., 2006), and also lead to cell death (Daraie et al., 2012). On the other hand, ROS production is highly in mitochondria and disruption of mitochondrial function can result in both apoptotic and necrotic cell death. As yet, no data clearly demonstrates that uranium can cause this type of damages in the brain. A recent study have suggested that in vitro depleted uranium lead to oxidative stress in isolated rat brain mitochondria and their dysfunctions (Shaki et al., 2013) which was not confirmed by another study in zebrafish model (Bourdineaud et al., 2013).

Mechanisms of anti-oxidative defense control the redox state of the cell, which is essential for normal physiological and biochemical functioning. Because modulation of their expression reflects potential oxidative stress, the principal antioxidant enzymes have been also examined, i.e., superoxide dismutase (SOD), catalase (CAT), glutathione peroxidase (GPx), and glutathione reductase (GR). Glutathione also plays an essential role in the detoxification of ROS in the brain, and its main function is to protect against oxidative stress. Therefore, several studies have also analyzed reduced (GSH) and oxidized (GSSG) glutathione. Their results show changes in the expression, protein levels, and activity of these different antioxidant agents after chronic highdose exposure for 3 months (Linares et al., 2007) and low-dose exposure for 9 months (Lestaevel et al., 2009)-both to depleted uranium. At the high dose, protein levels of GR and GPx decreased in the cortex, GR decreased in the hippocampus, and GPx increased in the cerebellum. Although CAT and SOD activities did not change in the cortex, CAT activity increased in the hippocampus and the cerebellum. In parallel, GSH levels decreased and GSSG levels increased in these two brain regions (Linares et al., 2007). At the low dose, gene expression of GP $x$ and SOD increased in the entorhinal cortex, without however any modification of their activity. In contrast, CAT activity increased without any change in its gene expression (Lestaevel et al., 2009).

The nitric oxide (NO) pathway also plays a key role in oxidative stress. NO is a free radical and a highly reactive species. At low concentrations, it performs protective or regulatory functions in cells, but has toxic effects at higher concentrations. Repeated injection of uranium at $0.1 \mathrm{mg} / \mathrm{kg}$ for 7 days increased NO levels in the cortex and brainstem, while these levels decreased in the same brain region after exposure at $1 \mathrm{mg} / \mathrm{kg}$ (Abou-Donia et al., 2002). In our laboratory, Lestaevel et al. (2009) showed an increase in inducible NO synthase expression after chronic exposure, without any modification of its activity. These results indicate that uranium exposure leads to some changes in the NO-ergic pathway that can have protective or neurotoxic effects, depending on the dose and duration of exposure. These effects also depend, however, on the uranium enrichment status, which influences the relative expression of chemical and radiological toxicity: depleted uranium appeared to induce antioxidant agents to counteract oxidative stress, whereas enriched uranium caused antioxidant activity to decrease (Lestaevel et al., 2009). This result may be linked to the

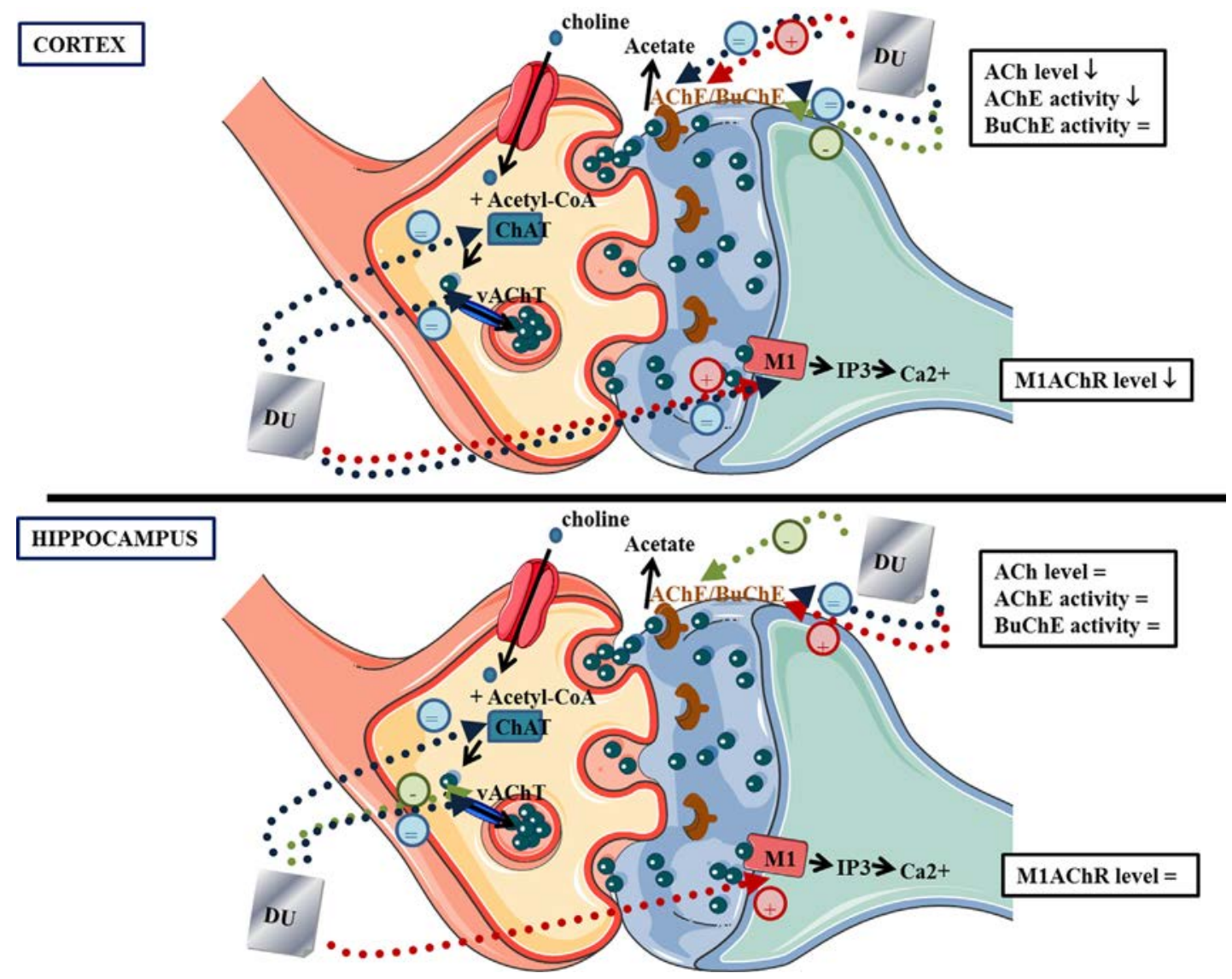

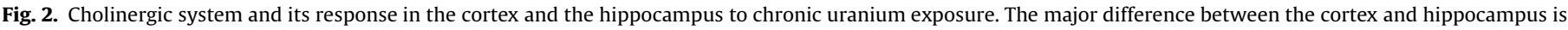

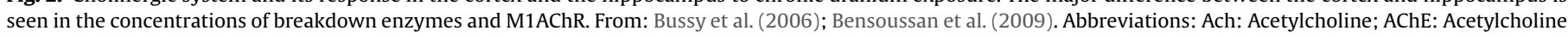

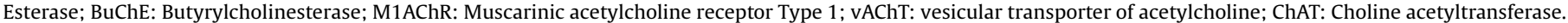

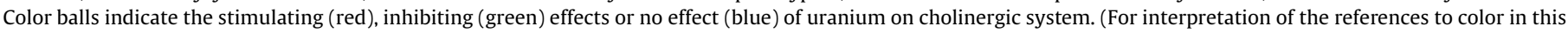
figure legend, the reader is referred to the web version of this article.) 
neurobehavioral changes observed after exposure to enriched but not depleted uranium (Houpert et al., 2005; Houpert et al., 2005a).

In conclusion, an imbalance of pro/antioxidant systems is certainly a mechanism that may play a role in the mechanistic pathways of uranium's effects on brain functions. Nonetheless, the results described above cannot be interpreted to demonstrate that uranium has a clear and unique effect on oxidative stress. They do, however, strongly suggest that uranium induces a response that depends on exposure time and dose to adapt to particular oxidative states and that this differs further by brain region. To illustrate, Fig. 1 is a representation of the opposite response of oxidative stress pathway when it chronically exposed to low versus high doses of depleted uranium. At low dose, the uranium appeared to stimulate tissue levels of several anti-oxidative enzymes (SOD, CAT and GPX) as well as NOS, when the tissue levels of these enzymes are unchanged (NOS, SOD, CAT) or decreased (GPx, GR) after high uranium dose.

\subsection{Neurotransmitter pathways}

Neurotransmitters play a fundamental role in various neurophysiological processes such as neurologic behavior. Among neurotransmitters, acetylcholine has been studied most.

\subsubsection{Cholinergic system and neurobehavioral functions}

Acetylcholine $(\mathrm{ACh})$ is an important neurotransmitter in the central nervous system and is known to be involved in higher brain functions, such as learning and memory (Drever et al., 2010; Hasselmo and Giocomo, 2006). ACh neurotransmission is also known to induce the changeover from non-rapid eye movement sleep to rapid eye movement (REM) sleep or wakefulness (Steriade, 2004). Finally, acetylcholinesterase (AChE) and acetylcholine receptor (AChR) may influence locomotor and sensorimotor performance (Gerber et al., 2001).

Cholinergic neurotransmission involves ACh synthesis and release. AChE can hydrolyze ACh on postsynaptic membranes, and AChE activity is a commonly used biomarker of neurotoxicity. Cholinergic neurons project from the brainstem to several regions, including the cortex, hippocampus, and cerebellum. These are the three principal rat brain regions studied most frequently. In the cortex, AChE activity increased after 1 month of daily intramuscular injection of depleted uranium at $1 \mathrm{mg} / \mathrm{kg}$ for 7 days, but not at $0.1 \mathrm{mg} / \mathrm{kg}$; this increase was associated with sensorimotor alterations (Abou-Donia et al., 2002). By contrast, AChE activity decreased in the entorhinal cortex after 1.5 and 9 months of chronic exposure to $2 \mathrm{mg} / \mathrm{kg} /$ day of depleted uranium in drinking water (Bensoussan et al., 2009), while AChE activity was not modified in the frontal cortex of rats exposed to uranium in their drinking water for 6 months (Bussy et al., 2006). Although AbouDonia et al. (2002) did not show any changes of AChE activity in the cerebellum of contaminated rats after repeated injections, this activity decreased after chronic exposure in drinking water (Bussy et al., 2006). Both time and mode of contamination differed in these two studies. Surprisingly, none of these studies observed any modification of AChE activity in the hippocampus (Bensoussan et al., 2009; Bussy et al., 2006). Various components of the cholinergic system were altered, however, such as gene expression of AChE or vesicular transporter of ACh (vAChT) or muscarinic receptor type $1(\mathrm{M} 1 \mathrm{AChR})$ in the hippocampus after subchronic and chronic exposure. These changes were not associated with modification of protein levels in the hippocampus, though, in contrast to the cortex where uranium exposure has been shown to lead to transcriptional dysregulation and translational changes. These induced a decrease in the protein levels of ACh, AChE, and M1AChR (Bensoussan et al., 2009). Fig. 2 illustrates the opposite effects of uranium on gene expression obtained in the cortex and the hippocampus following ingestion of uranium-contaminated drinking water. A diminution of vAChT mRNA was observed in the hippocampus, with no changes in cortex. An increase in AChE mRNA and a decrease in BuChE mRNA are induced in the cortex, while AChE mRNA was decreased and BuChE mRNA increased in the hippocampus. The M1AChR mRNA was increased in both cerebral areas. In terms of enzyme activities and protein levels, Fig. 2 indicates also a global inhibitory impact in the cortex and an absence of real impact in the hippocampus. Another outstanding point is that most changes were observed in trans- and postsynaptic mechanisms, when only minor changes were noted in presynaptic pathway.

These studies indicate that the cholinergic system - but not all its components - is affected by the chemotoxicity of uranium. The effects of uranium depend on brain region, duration of exposure, and uranium concentration. Moreover the cortex appears to be more sensitive to uranium than the hippocampus. These alterations may be correlated with the behavioral changes observed after uranium exposure in REM sleep, memory, and locomotor and sensorimotor performance (see part 1 ).

It is now necessary to explore how uranium might play its role on the cholinergic system. This role might be direct, due to uranium accumulation in the brain (although these are not always correlated). Cholinergic neurons can modulate dopaminergic, GABAergic or glutamatergic neurotransmission (Janhunen and Ahtee, 2007) and might thus play an indirect role in other neurotransmitter systems.

\subsubsection{Monoamine metabolism}

Dopamine is an inhibitory neurotransmitter known to be essential in locomotor activity (Schultz, 2007). It is involved in the control of movement and posture. Dopaminergic neurons principally project from the substantia nigra to the striatum and from the ventral tegmental area to the frontal cortex and hippocampus. Serotonin is known to play a role in different physiological functions, including sleep, food intake, cognitive functions, pain, anxiety, and depression (la Fleur and Serlie, 2014; Meneses and LiySalmeron, 2012; Monti, 2011). Serotoninergic neurons project principally from the raphe nuclei to the striatum, cortex, and hippocampus.

Subtle alterations of monoamine metabolism in specific brain regions have been shown in rats exposed to depleted uranium in their drinking water ( $2 \mathrm{mg} / \mathrm{kg} /$ day for $1.5,6$, and 9 months). After subchronic uranium exposure, the dopamine level in the hypothalamus decreased. In addition, the dopaminergic turnover ratio decreased in the cortex after 6 months and in the striatum after 9 months of exposure (Bussy et al., 2006). No modification of dopaminergic components was observed in the hippocampus in this study. Dopamine levels fell transiently in the striatum 3 days after an intramuscular injection of $1 \mathrm{mg} / \mathrm{kg}$ depleted uranium and returned to control levels 7 days after the injection (Barber et al., 2007); without any modification of 3,4 dihydroxyphenylacetic acid (DOPAC) levels and D2 receptors during this period. Like the dopaminergic system, serotoninergic turnover was also disrupted in the frontal cortex after 9 months of exposure (Bussy et al., 2006). Serotoninergic components were not modified in either the hippocampus or the striatum. Neither the dopaminergic nor the serotoninergic metabolism was modified in any of the brain regions studied (the cortex, striatum hippocampus, and cerebellum) in rats contaminated for a month through their drinking water ( $2 \mathrm{mg} / \mathrm{kg} /$ day of depleted uranium) (Houpert et al., 2004). Similarly, intramuscular injection of $0.1,0.3$, or $1 \mathrm{mg} / \mathrm{kg}$ depleted uranium did not alter serotonin levels in the striatum, hippocampus, cerebellum, or cortex (Barber et al., 2007). 
In summary, subtle neurochemical effects on monoaminergic systems indicate that uranium-associated modifications to the monoamine metabolism are chronic and progressive. These results suggest that the decrease in monoamine levels may result from a decrease in monoamine anabolism.

Thus, neither short- nor long-term uranium exposure appears to have a specific target in the neurotransmitter system. The data do not indicate that uranium affects the whole brain but rather that its effects are specific to each brain area and change over time.

\subsection{Neurophysiological properties}

The literature about the physiological properties of neurotransmission after uranium exposure is exceedingly sparse. The only brain region in which these properties have been studied is the hippocampus. Changes in electrophysiological potentials in the hippocampus have been demonstrated in animals chronically exposed to depleted uranium pellets at low (4 pellets, $120 \mathrm{mg}$ ), medium (10 pellets, $300 \mathrm{mg}$ ), and high ( 20 pellets, $600 \mathrm{mg}$ ) doses (Pellmar et al., 1999a). The ability of the synaptic potential to elicit the population spike (i.e., the $\mathrm{E} / \mathrm{S}$ coupling) was impaired in the rats with 6 and 12 months of high-dose exposure and led to decreased neuronal excitability in CA1 region. These results suggest that uranium changes the efficacy of synaptic transmission and may thus directly affect the "enter-exit" functions of the neuron. These functions are essential to guarantee both the efficacy of information transmission between neurons and synaptic plasticity, which is one of the important neurochemical foundations of learning and memory. Long-term potentiation (LTP) is a learning and memory mechanism at the cellular level that is based on lasting synaptic plasticity (Neves et al., 2008) and is induced in CA1 by high-frequency stimulation of Schaffer collaterals. Therefore, the uranium-associated changes in E/S coupling observed in CA1 may induce LTP changes.

The effect of acute uranium exposure on hippocampal GABAergic and glutamatergic neurotransmission has been examined in vitro (Vietti and Lasley, 2007): uranium was applied to hippocampal synaptosomes via superfusing buffer to estimate its inhibitory/stimulatory potency on the endogenous transmitter release component. Depolarization-evoked glutamate decreased but GABA release was not affected after uranium application. The inhibitory potency of uranium on glutamate release appeared similar to that of other divalent metal ions acting at voltagesensitive calcium channels (Tomsig and Suszkiw, 1996). Nevertheless, uranium did not seem to show calcium-mimetic properties in this experimental protocol.

In conclusion, these data strongly suggest that uranium can alter the efficacy of synaptic transmission and glutamatergic
A

\section{control}

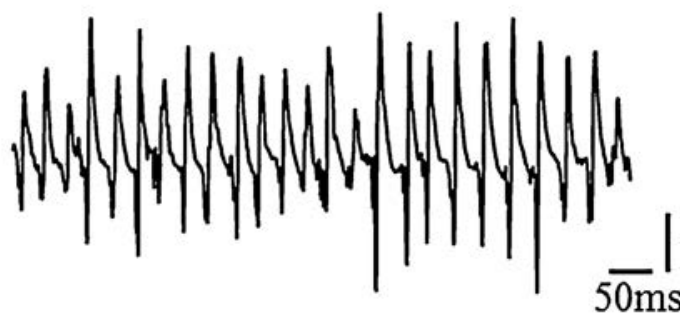

DU10

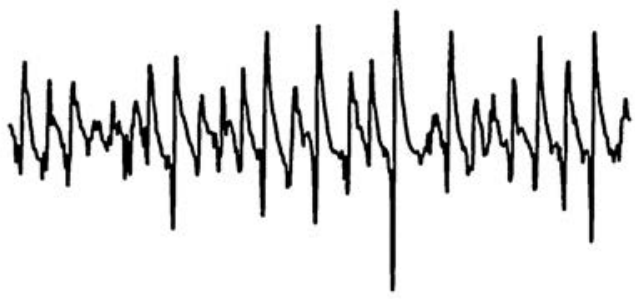

DU40

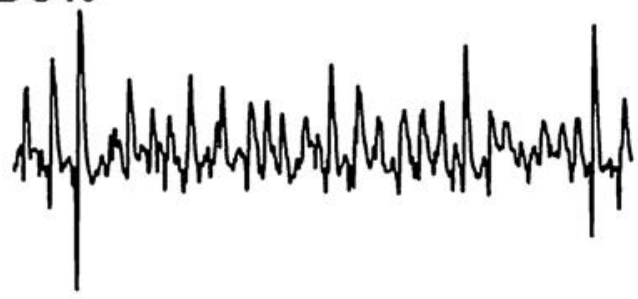

B
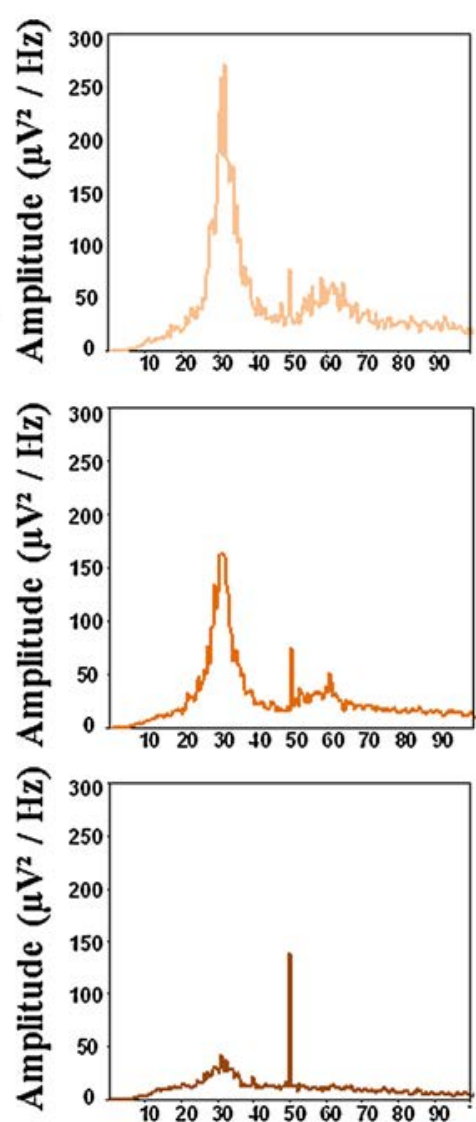

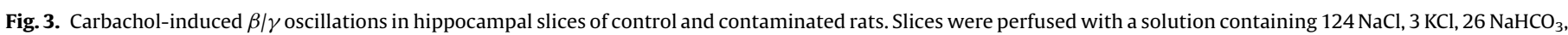

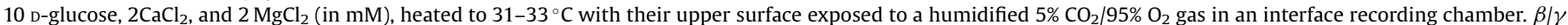

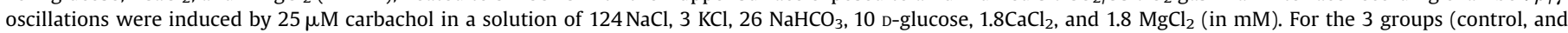

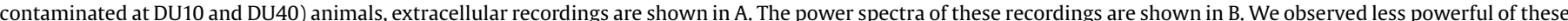

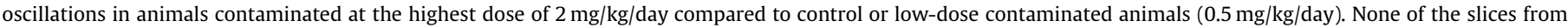

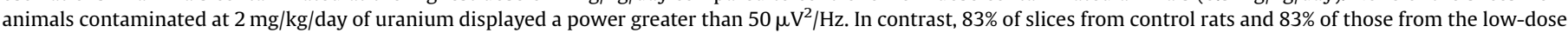

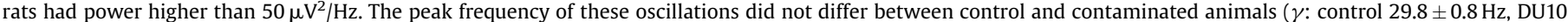

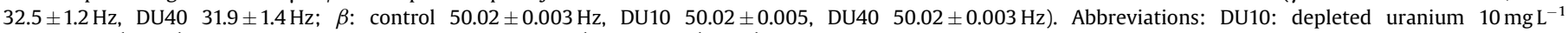
$\left(=0.5 \mathrm{mg} \mathrm{kg}^{-1} \mathrm{day}^{-1}\right)$ group, DU40: depleted uranium $40 \mathrm{mg} \mathrm{L}^{-1}\left(=2 \mathrm{mg} \mathrm{kg}^{-1} \mathrm{day}^{-1}\right)$ group. 
release in the hippocampus of rat brains. These changes lead to decreased neuronal excitability and to attenuation of the ability to support synaptic plasticity changes in synaptic function, which may contribute to cognitive deficits.

\section{Mechanistic pathways in brains "under construction"}

The immature brain is known to be more sensitive to pollutants than the adult brain (Grandjean and Landrigan, 2014; Rice and Barone, 2000). Little is known about neurobehavioral effects of uranium exposure (see part 1) or the mechanisms underlying these effects during the sensitive early life stages of rats. Exposure to depleted uranium during gestation and lactation induced changes in postnatal development and behavior of offspring (Houpert et al., 2007b; Sanchez et al., 2006). These results lead to the hypothesis that neurogenesis is impaired during the brain development of uranium-exposed embryos and pups (Legrand et al., 2014).

Impairments of object recognition memory, anxiety- and depressive-like behaviors were recently demonstrated in young adult rats after contamination by uranium from birth to 10 weeks at a dose of $2 \mathrm{mg} / \mathrm{kg} /$ day (Lestaevel et al., 2013, 2015). In this experimental protocol, named as the postnatal model, uranium exposure also led to an imbalance of pro/antioxidant systems in the hippocampus (Lestaevel et al., 2015) and to decreases in both ACh concentration and AChE activity in the entorhinal cortex (Lestaevel et al., 2013). As in adults, these two components of the cholinergic pathway were not modified in the hippocampus (Bensoussan et al., 2009; Bussy et al., 2006).

We are also starting to use this postnatal model to investigate synchronous network activity in the CA3 region of the hippocampus in uranium-contaminated rats. It has been known for some 25 years that rhythmic neuronal activities occur in the hippocampus during several behavioral states (Buzsaki, 1989). Among these network activities, gamma-frequency oscillation is known to be important in memory processes. High-frequency oscillations in the beta $(\beta, 13-30 \mathrm{~Hz})$ and gamma $(\gamma, 30-70 \mathrm{~Hz})$ ranges have been found in many parts of the brain and are associated with attention and perception (Arai and Natsume, 2006; Fellous and Sejnowski, 2000); they have also been linked to cognitive processing and working memory in humans (Howard et al., 2003; Tallon-Baudry et al., 1998) and animals (Fries et al., 2001; Pesaran et al., 2002). Therefore, $\beta / \gamma$ oscillations were analyzed in the CA3 region of hippocampus slices of 2 -month-old rats. The results of this study revealed impairments in the $\beta$ range activities and suggest that synchronous oscillations may be disrupted by chronic uranium exposure (Dinocourt et al., 2014) (Fig. 3). Because $\beta / \gamma$ oscillations are shown to play a role in novelty detection (Berke et al., 2008; França et al., 2014) and a decrease in $\beta / \gamma$ oscillations has been associated with increased novelty-induced exploration and behavioral alterations during object recognition tasks (Steullet et al., 2010), our data suggest that changes in $\beta / \gamma$ oscillations due to postnatal brain uranium exposure can impair object recognition memory. Further experiments, especially on basal neurotransmission and excitability as well as interneuron networks, are necessary to confirm these data.

In conclusion, these data demonstrate that the developing brain is, like the adult brain, affected by uranium exposure. They also indicate a lack of information about the effects of uranium on developmental processes.

\subsection{Conclusion}

In conclusion, uranium is present and physiologically active in the brain. Neurotoxicity induced by uranium involves: imbalance of the anti/pro-oxidant system as well as neurochemical and neurophysiological impairments. In addition, its effects appear to be specific according to brain area, dose, and duration of exposure. From these data, further investigations can be proposed to look into the understanding of uranium's effects on cerebral functions.

\section{Major conclusions and future investigations}

This review demonstrates that uranium's effects on the central nervous system are relatively well documented. Major conclusions are:

1) It is evident that uranium is present in the brain and it is also clear that its action may be selective according to cerebral area and is not necessarily correlated with the accumulation of uranium. However, the mechanisms by which uranium enters the brain are not yet clearly elucidated.

2) Experimental studies indicated that uranium exposure induced changes in animals suggesting a central effect of uranium such as on locomotion, sleep-wake cycle, and cognitive functions.

3) Uranium acts on different targets, affecting enzyme activity as well as gene and protein expression. Nevertheless, no correlation is usually found between gene expression and enzymatic activity. Therefore, transcriptional and post-transcriptional events occurred after uranium exposure

4) Brain during development seems more sensitive than adult brain when exposed to depleted uranium. This observation has to be confirmed after exposure to natural as well as enriched uranium.

5) Assessment of the health risks from uranium exposure is principally based on its chemical rather than its radiological toxicity, and most of the studies seeking to identify the mechanisms by which it induces behavioral alterations are investigated with depleted uranium. On the other hand, behavioral alterations are most clearly visible after chronic exposure to enriched uranium.

Further investigations are therefore needed to answer some of the questions on uranium neurotoxicity research. Specifically, it is necessary to clarify how and where uranium enter into the brain (region-specific permeability of the blood brain barrier, systemic pathway, transporter) and, more importantly, to determine the correlation between uranium's effects and its accumulation.

Behavioral changes observed in animal exposed to uranium are the reflection of disturbances in neurochemical and neurophysiological properties. Uranium's effects on neurotransmitter metabolism have been well studied for acetylcholine, compared to other neurotransmitters. On the other hand, chemical neurotransmission and electrophysiological properties have not been studied in detail. Consequently, amino acid neurotransmission (for example, glutamate and GABA) as well as the properties of synaptic transmission (for example, excitability, long-term potentiation, and neuronal network oscillations) must be investigated in-depth. Further experiments are also necessary to determine if uranium plays a direct or indirect role. For example, as previous studies have shown in lungs and kidneys (Periyakaruppan et al., 2007; Yazzie et al., 2003), uranium effects on transcriptional and posttranscriptional events and DNA damage must be explored more fully, together with the involvement of reactive oxygen species.

Little is known about effects of uranium on brain during development and the subsequent impact on cerebral function in adulthood. It is well demonstrated that exposure to toxicants in early life may cause later health effects. The brain is more sensitive during its development. Impairments during the different steps of proliferation, differentiation, migration, or synaptogenesis might lead to defects in neuronal network organization and consequently lead to behavioral disorders in adulthood. Moreover, epigenetic alterations are a possible mechanistic pathway. As a heavy metal, 
uranium might also alter DNA methylation (Miller et al., 2009), and this could be a part of the mechanism by which in utero or early postnatal uranium exposure affects cognitive functions in adult life. Thus, further attention and exploration are required to both the long-term consequences of uranium exposure during development and the mechanisms by which developmental processes are altered.

Finally, the question of whether or not long-term low-level uranium exposure is a hazard to human health is a new one. It appears that the release of uranium into the environment presents a threat to human health, but further studies are needed to examine exposure to uranium and its potential behavioral consequences.

\section{Acknowledgments}

We thank Audrey Legendre, Jean-Marc Bertho and François Paquet for their critical reading of the manuscript. We also thank Chrystelle Ibanez for her revision of an earlier version of the manuscript. Finally we thank Eric Samson and Estelle Rage for analysis of epidemiological studies on nuclear workers.

\section{References}

Abou-Donia, M.B., Dechkovskaia, A.M., Goldstein, L.B., Shah, D.U., Bullman, S.L., Khan, W.A., 2002. Uranyl acetate-induced sensorimotor deficit and increased nitric oxide generation in the central nervous system in rats. Pharmacol. Biochem. Behav. 72, 881-890.

Albina, M.L., Bellés, M., Linares, V., Sánchez, D.J., Domingo, J.L., 2005. Restraint stress does not enhance the uranium-induced developmental and behavioral effects in the offspring of uranium-exposed male rats. Toxicology 215, 69-79.

ATSDR (Agency for Toxic Substances and Dusease Regustry, 2013. Toxicological Profile for Uranium. U.S. Department of Health and Human Services, Public Health Service, Atlanta, GA.

Arai, J., Natsume, K., 2006. The properties of carbachol-induced beta oscillation in rat hippocampal slices. Neurosci. Res. 54, 95-103.

Arfsten, D.P., Wilfong, E.R., Bekkedal, M.Y., Johnson, E.W., McInturf, S.M., Eggers, J.S., Schaeffer, D.J., Still, K.R., 2007. Evaluation of the effect of implanted depleted uranium (DU) on adult rat behavior and toxicological endpoints. J. Toxicol. Environ. Health A 70, 1995-2010.

Barber, D.S., Ehrich, M.F., Jortner, B.S., 2005. The effect of stress on the temporal and regional distribution of uranium in rat brain after acute uranyl acetate exposure. J. Toxicol. Environ. Health A 68, 99-111.

Barber, D.S., Hancock, S.K. McNally, A.M., Hinckley, J., Binder, E., Zimmerman, K., Ehrich, M.F., Jortner, B.S., 2007. Neurological effects of acute uranium exposure with and without stress. Neurotoxicology 28, 1110-1119.

Basset, C., Averseng, O., Ferron, P.J., Richaud, N., Hagège, A., Pible, O., Vidaud, C., 2013. Revision of the biodistribution of uranyl in serum: is fetuin-A the major protein target? Chem. Res. Toxicol. 26, 645-653.

Bellés, M., Albina, M.L., Linares, V., Gómez, M., Sánchez, D.J., Domingo, J.L., 2005. Combined action of uranium and stress in the rat. I. Behavioral effects. Toxicol Lett. 158, 176-185.

Bensoussan, H., Grandcolas, L., Dhieux-Lestaevel, B., Delissen, O., Vacher, C.M., Dublineau, I., Voisin, P., Gourmelon, P., Taouis, M., Lestaevel, P., 2009. Heavy metal uranium affects the brain cholinergic system in rat following sub-chronic and chronic exposure. Toxicology 261, 59-67.

Berke, H., Rothstein, A., 1949. Amino aciduria in uranium poisoning; the response to different amounts of uranium given intravenously and by inhalation. J. Pharmacol. Exp. Ther. 96, 198-208.

Berke, J.D., Hetrick, V., Breck, J., Greene, R.W., 2008. Transient 23-30 Hz oscillations in mouse hippocampus during exploration of novel environments. Hippocampus 18, 519-529.

Blanck, R.R., Hiatt, J., Hyams, K.C., Kang, H., Mather, S., Murphy, F., Roswell, R., Thacker, S.B., 1995. Unexplained illnesses among desert storm veterans: a search for causes, treatment, and cooperation. Arch. Int. Med. 155, 262-268.

Bleise, A., Danesi, P.R., Burkart, W., 2003. Properties, use and health effects of depleted uranium (DU): a general overview. J. Environ. Radioact. 64, 93-112.

Boice, J.D., Cohen, S.S., Mumma, M.T., Dupree Ellis, E., Eckerman, K.F., Leggett, R.W. Boecker, B.B., Brill, A.B., Henderson, B.E., 2006. Mortality among radiation workers at Rocketdyne (Atomics International), 1948-1999. Radiat. Res. 166, 98-115.

Born, J., DeKloet, E.R., Wenz, H., Kern, W., Fehm, H.L., 1991. Gluco- and antimineralocorticoid effects on human sleep: a role of central corticosteroid receptors. Am. J. Physiol. 260, E183-E188.

Bourdineaud, J.P., Rossignol, R., Brèthes, D., 2013. Zebrafish: a model animal for analyzing the impact of environmental pollutants on muscle and brain mitochondrial bioenergetics. Int. J. Biochem. Cell. Biol. 45, 16-22.

Briner, W., Abboud, B., 2002. Behavior of juvenile mice chronically exposed to depleted uranium. In: Khassanova, L., Collery, Ph., Maymard, I., Khassanova, Z.
Etienne, J.C. (Eds.), Metal Ions in Biology and Medicine. John Libby Eurotext, Paris, pp. 353-356.

Briner, W., Davis, D., 2002. Lipid oxidation and behavior are correlated in depleted uranium exposed mice. In: Khassanova, L., Collery, P., Maymard, I., Khassanova, Z., Etienne, J.C. (Eds.), Metal Ions in Biology and Medicine, 7. John Libby Eurotext, Paris, pp. 59-63.

Briner, W., Murray, J., 2005. Effects of short-term and long-term depleted uranium exposure on open-field behavior and brain lipid oxidation in rats. Neurotoxicol. Teratol. 27, 135-144.

Bussy, C., Lestaevel, P., Dhieux, B., Amourette, C., Paquet, F., Gourmelon, P., Houpert, P. 2006. Chronic ingestion of uranyl nitrate perturbs acetylcholinesterase activity and monoamine metabolism in male rat brain. Neurotoxicology 27, 245-252.

Buzsaki, G., 1989. Two-stage model of memory trace formation: a role for noisy brain states. Neuroscience 31, 551-570.

Canu, I.G., Laurent, O., Pires, N., Laurier, D., Dublineau, I., 2011. Health effects of naturally radioactive water ingestion: the need for enhanced studies. Environ. Health Perspect. 119, 1676-1680.

Carpenter, A.V., Flanders, W.D., Frome, E.L., Tankerley, W.G., Fry, S.A., 1988. Chemical exposures and central nervous system cancers: a case-control study among workers at two nuclear facilities. Am. J. Ind. Med. 13, 351-362.

Checkoway, H., Pearce, N., Crawford-Brown, D.J., Cragle, D.L., 1988. Radiation doses and cause-specific mortality among workers at a nuclear materials fabrication plant. Am. J. Epidemiol. 127, 255-266.

Daraie, B., Pourahmad, J., Hamidi-Pour, N., Hosseini, M.J, Shaki, F, Soleimani, M., 2012. Uranyl acetate induces oxidative stress and mitochondrial membrane potential collapse in the human dermal fibroblast primary cells. Iran. J. Pharm. Res. 11, 495-501.

Dinocourt C., Stefani J., Elie C., Lestaevel P., Dublineau I., Gourmelon P., 2014. Reduced carbachol-induced beta/gamma oscillations in CA3 region of hippocampus after post-natal contamination of uranium in adult rat. Meeting abstract, Neurosciences 2014. Washington, D.C.

Dobson, A.W., Lack, A.K., Erikson, K.M., Aschner, M., 2006. Depleted uranium is not toxic to rat brain endothelial (RBE4) cells. Biol. Trace Elem. Res. 110, 61-72.

Domingo, J.L., 2001. Reproductive and developmental toxicity of natural and depleted uranium: a review. Reprod. Toxicol. 15, 603-609.

Drever, B.D., Riedel, G., Platt, B., 2010. The cholinergic system and hippocampal plasticity. Behav. Brain. Res. 221, 505-514.

Dublineau I., Souidi M., Gueguen Y., Lestaevel P., Bertho J.M., Manens L., Delissen O. Grison S., Paulard A., Monin A., Kern Y., Rouas C., Loyen J., Gourmelon P., Aigueperse J., 2014. Unexpected lack of deleterious effects of uranium on physiological systems following a chronic oral intake in adult rat. Biomed Res Int, 2014:181989 (online).

Eriksson, P., Fischer, C., Stenerlöw, B., Fredriksson, A., Sundell-Bergman, S., 2010. Interaction of gamma-radiation and methyl mercury during a critical phase of neonatal brain development in mice exacerbates developmental neurobehavioural effects. Neurotoxicology 31, 223-229.

Fellous, J.M., Sejnowski, T.J., 2000. Cholinergic induction of oscillations in the hippocampal slice in the slow $(0.5-2 \mathrm{~Hz})$, theta $(5-12 \mathrm{~Hz})$, and gamma (35$70 \mathrm{~Hz}$ ) bands. Hippocampus 10, 187-197.

Fitsanakis, V.A., Erikson, K.M., Garcia, S.J., Evje, L., Syversen, T., Aschner, M., 2006. Brain accumulation of depleted uranium in rats following 3- or 6-month treatment with implanted depleted uranium pellets. Biol. Trace Elem. Res. 111, 185-197.

França, A.S., do Nascimento, G.C., Lopes-dos-Santos, V., Muratori, L., Ribeiro, S., Lobao-Soares, B., Tort, A.B., 2014. Beta2 oscillations $(23-30 \mathrm{~Hz})$ in the mouse hippocampus during novel object recognition. Eur. J. Neurosci. 40, 3693-3703.

Fries, P., Reynolds, J.H., Rorie, A.E., Desimone, R., 2001. Modulation of oscillatory neuronal synchronization by selective visual attention. Science 291, 1560-1563.

Fukuda, S., Ikeda, M., Chiba, M. Kaneko, K., 2006. Clinical diagnostic indicators of renal and bone damage in rats intramuscularly injected with depleted uranium. Radiat. Prot. Dosimetry 118, 307-314.

Gerber, D.J., Sotnikova, T.D., Gainetdinov, R.R., Huang, S.Y., Caron, M.G., Tonegawa, S., 2001. Hyperactivity, elevated dopaminergic transmission, and response to amphetamine in M1 muscarinic acetylcholine receptor-deficient mice. Proc. Natl. Acad. Sci. U. S. A. 98, 15312-15317.

Ghosh, S., Kumar, A., Pandey, B.N., Mishra, K.P., 2007. Acute exposure of uranyl nitrate causes lipid peroxidation and histopathological damage in brain and bone of Wistar rat. J. Environ. Pathol. Toxicol. Oncol. 26, 255-261.

Gilman, A.P., Villeneuve, D.C., Secours, V.E., Yagminas, A.P., Tracy, B.L., Quinn, J.M., Valli, V.E., Willes, R.J., Moss, M.A., 1998. Uranyl nitrate: 28-day and 91-day toxicity studies in the Sprague-Dawley rat. Toxicol. Sci. 41, 117-128.

Goasguen, J., Lapresle, J., Ribot, C., Rocquet, G., 1982. Chronic neurological syndrome resulting from intoxication with metallic uranium. Nouv. Presse Med. 11, 119121.

Grandjean, P., Landrigan, P.J., 2014. Neurobehavioural effects of developmental toxicity. Lancet Neurol. 13, 330-338.

Hasselmo, M.E., Giocomo, L.M., 2006. Cholinergic modulation of cortical function. J. Mol. Neurosci. 30, 133-135.

Hémadi, M., Ha-Duong, N.T., Plantevin, S., Vidaud, C., El Hage Chahine, J.M., 2010. Can uranium follow the iron-acquisition pathway? Interaction of uranyl-loaded transferrin with receptor. J. Biol. Inorg. Chem. 15, 497-504.

Hilfiker, H., Hattenhauer, O., Traebert, M., Forster, I., Murer, H., Biber, J., 1998. Characterization of a murine type II sodium-phosphate cotransporter expressed in mammalian small intestine. Proc. Natl. Acad. Sci. U. S. A. 95, 14564-14569. 
Houpert, P., Lestaevel, P., Amourette, C., Dhieux, B., Bussy, C., Paquet, F., 2004. Effect of $U$ and 137 Cs chronic contamination on dopamine and serotonin metabolism in the central nervous system of the rat. Can. J. Physiol. Pharmacol. 82, 161-166.

Houpert, P., Lestaevel, P., Bussy, C., Paquet, F., Gourmelon, P., 2005. Enriched but not depleted uranium affects central nervous system in long-term exposed rat. Neurotoxicology 26, 1015-1020.

Houpert, P., Bizot, J.C., Bussy, C., Dhieux, B., Lestaevel, P., Gourmelon, P., Paquet, F. 2007a. Comparison of the effects of enriched uranium and 137-cesium on the behaviour of rats after chronic exposure. Int. J. Radiat. Biol 83, 99-104.

Houpert, P., Frelon, S., Lestaevel, P., Bussy, C., Gourmelon, P., Paquet, F., 2007b. Parental exposure to enriched uranium induced delayed hyperactivity in rat offspring. Neurotoxicology 28, 108-113.

Houpert, P., Frelon, S., Monleau, M., Bussy, C., Chazel, V., Paquet, F., 2007c. Heterogeneous accumulation of uranium in the brain of rats. Radiat. Prot. Dosimetry $127,86-89$.

Howard, M.W., Rizzuto, D.S., Caplan, J.B., Madsen, J.R., Lisman, J., AschenbrennerScheibe, R., Schulze-Bonhage, A., Kahana, M.J., 2003. Gamma oscillations correlate with working memory load in humans. Cereb Cortex 13, 1369-1374.

Howland, J.W., 1948. Comprehensive summary of the pharmacology and toxicology of uranium compounds; studies on human exposures to uranium compounds. At. Energy Biophys. Biol. Med. 1, 174.

Ibanez, C., Suhard, D., Tessier, C., Delissen, O., Lestaevel, P., Dublineau, I., Gourmelon, P., 2014. Intranasal exposure to uranium results in direct transfer to the brain along olfactory nerve bundles. Neuropathol. Appl. Neurobiol. 40, 477-488.

Inden, M., Iriyama, M., Takagi, M., Kaneko, M., Hozumi, I., 2013. Localization of typeIII sodium-dependent phosphate transporter 2 in the mouse brain. Brain Res. 1531, 75-83.

Janhunen, S., Ahtee, L., 2007. Differential nicotinic regulation of the nigrostriatal and mesolimbic dopaminergic pathways: implications for drug development. Neurosci. Biobehav. Rev. 31, 287-314.

Jouvet, M., 1994. Paradoxical sleep mechanisms. Sleep 17, S77-S83.

Konietzka, R., Heinze, R., Seiwert, M., Dieter, H.H., 2014. The ex-vivo intestinal absorption rate of uranium is a two-phase function of supply. Regul. Toxicol. Pharmacol. 69, 256-262.

la Fleur, S.E., Serlie, M.J., 2014. The interaction between nutrition and the brain and its consequences for body weight gain and metabolism; studies in rodents and men. Best Pract. Res. Clin. Endocrinol. Metab. 28, 649-659.

Legrand M., Ibanez C., Lestaevel P., Stefani J., Florès N., Eriksson P., Dinocourt C., 2014 Is neurogenesis altered after chronic internal contamination of uranium during brain development? Meeting abstract, Neurosciences 2014. Washington, D.C.

Lemercier, V., Millot, X., Ansoborlo, E., Ménétrier, F., Flüry-Hérard, A., Rousselle, C.H., Scherrmann, J.M., 2003. Study of uranium transfer across the blood-brain barrier. Radiat. Prot. Dosimetry 105, 243-245.

Lestaevel, P., Bussy, C., Paquet, F., Dhieux, B., Clarençon, D., Houpert, P., Gourmelon, P., 2005a. Changes in sleep-wake cycle after chronic exposure to uranium in rats. Neurotoxicol. Teratol. 27, 835-840.

Lestaevel, P., Houpert, P., Bussy, C., Dhieux, B., Gourmelon, P., Paquet, F., 2005b. The brain is a target organ after acute exposure to depleted uranium. Toxicology 212, 219-226.

Lestaevel, P., Romero, E., Dhieux, B., Bensoussan, H., Berradi, H., Dublineau, I., Voisin, P., Gourmelon, P., 2009. Different pattern of brain pro-/anti-oxidant activity between depleted and enriched uranium in chronically exposed rats. Toxicology 258, 1-9.

Lestaevel, P., Bensoussan, H., Dhieux, B., Delissen, O., Vacher, C.M., Dublineau, I. Voisin, P., Taouis, M., 2013. Cerebral cortex and hippocampus respond differently after post-natal exposure to uranium. J. Toxicol. Sci. 38, 803-811.

Lestaevel, P., Airault, F., Racine, R., Bensoussan, H., Dhieux, B., Delissen, O., Manens, L., Aigueperse, J., Voisin, P., Souidi, M., 2014. Influence of environmental enrichment and depleted uranium on behaviour, cholesterol and acetylcholine in apolipoprotein E-deficient mice. J. Mol. Neurosci. 53, 469-479.

Lestaevel, P., Dhieux, B., Delissen, O., Benderitter, M., Aigueperse, J., 2015. Uranium modifies or not behavior and antioxidant status in the hippocampus of rats exposed since birth. J. Toxicol. Sci. 40, 99-107.

Linares, V., Sanchez, D.J., Belles, M., Albina, L., Gomez, M., Domingo, J.L., 2007. Prooxidant effects in the brain of rats concurrently exposed to uranium and stress. Toxicology 236, 82-91.

Liu, J., Lewis, G., 2014. Environmental toxicity and poor cognitive outcomes in children and adults. J. Environ. Health 76, 130-138.

Macfarlane, G.J., Biggs, A.-M., Maconochie, N., Hotopf, M., Doyle, P., Lunt, M., 2003. Incidence of cancer among UK Gulf war veterans: cohort study. Br. Med. J. 327, 1373-1375.

McDiarmid, M.A., Hooper, F.J., Squibb, K., McPhaul, K., Engelhardt, S.M., Kane, R., DiPino, R., Kabat, M., 2002. Health effects and biological monitoring results of Gulf War veterans exposed to depleted uranium. Mil. Med. 167, 123-124.

McDiarmid, M.A., Engelhardt, S.M., Oliver, M., Gucer, P., Wilson, P.D., Kane, R., Kabat, M., Kaup, B., Anderson, L., Hoover, D., Brown, L., Albertini, R.J., Gudi, R., JacobsonKram, D., Thorne, C.D., Squibb, K.S., 2006. Biological monitoring and surveillance results of Gulf War I veterans exposed to depleted uranium. Int. Arch. Occup. Environ. Health 79, 11-21.

McDiarmid, M.A., Gaitens, J.M., Hines, S., Breyer, R., Wong-You-Cheong, J.J., Engelhardt, S.M., Oliver, M., Gucer, P., Kane, R., Cernich, A., Kaup, B., Hoover, D. Gaspari, A.A., Liu, J., Harberts, E., Brown, L., Centeno, J.A., Gray, P.J., Xu, H., Squibb, K.S., 2013. The Gulf War depleted uranium cohort at 20 years: bioassay results and novel approaches to fragment surveillance. Health Phys. 104, 347-361.

Meneses, A., Liy-Salmeron, G., 2012. Serotonin and emotion, learning and memory. Rev. Neurosci. 23, 543-553.
Miller, A.C., Stewart, M., Rivas, R., 2009. DNA methylation during depleted uraniuminduced leukemia. Biochimie 91, 1328-1330.

Monleau, M., Bussy, C., Lestaevel, P., Houpert, P., Paquet, F., Chazel, V., 2005. Bioaccumulation and behavioural effects of depleted uranium in rats exposed to repeated inhalations. Neurosci. Lett. 390, 31-36.

Monti, J.M., 2011. Serotonin control of sleep-wake behavior. Sleep. Med. Rev. 15, 269-281.

Neves, G., Cooke, S.F., Bliss, T.V., 2008. Synaptic plasticity, memory and the hippocampus: a neural network approach to causality. Nat. Rev. Neurosci. 9, 6575.

Muller, D., Houpert, P., Cambar, J., Hengé-Napoli, M.H., 2006. Role of the sodiumdependent phosphate co-transporters and of the phosphate complexes of uranyl in the cytotoxicity of uranium in LLC-PK1 cells. Toxicol. Appl. Pharmacol. 214, 166-177.

Ortega, A., Domingo, J.L., Llobet, J.M., Tomás, J.M., Paternain, J.L., 1989. Evaluation of the oral toxicity of uranium in a 4-week drinking-water study in rats. Bull. Environ. Contam. Toxicol. 42, 935-941.

Paquet, F., Houpert, P., Blanchardon, E., Delissen, O., Maubert, C., Dhieux, B., Moreels, A.M., Frelon, S., Gourmelon, P., 2006. Accumulation and distribution of uranium in rats after chronic exposure by ingestion. Health Phys. 90, 139-147.

Paternain, J.L., Domingo, J.L., Ortega, A., Llobet, J.M., 1989. The effects of uranium on reproduction, gestation, and postnatal survival in mice. Ecotoxicol. Environ. Saf. 17, 291-296.

Pellmar, T.C., Keyser, D.O., Emery, C., Hogan, J.B., 1999a. Electrophysiological changes in hippocampal slices isolated from rats embedded with depleted uranium fragments. Neurotoxicology 20, 785-792.

Pellmar, T.C., Fuciarelli, A.F., Ejnik, J.W., Hamilton, M., Hogan, J., Strocko, S., Emond, C., Mottaz, H.M., Landauer, M.R., 1999b. Distribution of uranium in rats implanted with depleted uranium pellets. Toxicol. Sci. 49, 29-39.

Periyakaruppan, A., Kumar, F., Sarkar, S., Sharma, C.S., Ramesh, G.T., 2007. Uranium induces oxidative stress in lung epithelial cells. Arch. Toxicol. 81, 389-395.

Pesaran, B., Pezaris, J.S., Sahani, M., Mitra, P.P., Andersen, R.A., 2002. Temporal structure in neuronal activity during working memory in macaque parietal cortex. Nat. Neurosci. 5, 805-811.

Poisson, C., Stefani, J., Manens, L., Delissen, O., Suhard, D., Tessier, C., Dublineau, I., Guéguen, Y., 2014. Chronic uranium exposure dose-dependently induces glutathione in rats without any nephrotoxicity. Free Radic. Res. 48, 1218-1231.

Pourahmad, J., Ghashang, M., Ettehadi, H.A., Ghalandari, R., 2006. A search for cellular and molecular mechanisms involved in depleted uranium (DU) toxicity. Environ. Toxicol. 21, 349-354.

Rage, E., Caër-Lorho, S., Drubay, D., Ancelet, S., Laroche, P., Laurier, D., 2015. Mortality analyses in the updated French cohort of uranium miners (1946-2007). Int. Arch. Occupat. Environ. Health 88, 717-730.

Rice, D., Barone Jr., S., 2000. Critical periods of vulnerability for the developing nervous system: evidence from humans and animal models. Environ. Health Perspect. 108 (Suppl. 3), 511-533.

Rouas, C., Bensoussan, H., Suhard, D., Tessier, C., Grandcolas, L., Rebiere, F., Dublineau, I., Taouis, M., Pallardy, M., Lestaevel, P., Gueguen, Y., 2010. Distribution of soluble uranium in the nuclear cell compartment at subtoxic concentrations. Chem. Res. Toxicol. 23, 1883-1889.

Rubaj, A., Zgodziński, W., Sieklucka-Dziuba, M., 2003. The influence of adenosine A3 receptor agonist: IB-MECA, on scopolamine- and MK-801-induced memory impairment. Behav. Brain Res. 141, 11-17.

Sanchez, D.J., Belles, M., Albina, M.L., Gomez, M., Linares, V., Domingo, J.L., 2006. Exposure of pregnant rats to uranium and restraint stress: effects on postnata development and behavior of the offspring. Toxicology 228, 323-332.

Schultz, W., 2007. Multiple dopamine functions at different time courses. Annu. Rev. Neurosci. 30, 259-288.

Shaki, F., Hosseini, M.J., Ghazi-Khansari, M., Pourahmad, J., 2013. Depleted uranium induces disruption of energy homeostasis and oxidative stress in isolated rat brain mitochondria. Metallomics 5, 736-744.

Squibb, K.S., Gaitens, J.M., Engelhardt, S., Centeno, J.A., Xu, H., Gray, P., McDiarmid, M A., 2012. Surveillance for long-term health effects associated with depleted uranium exposure and retained embedded fragments in US veterans. J. Occup. Environ. Med. 54, 724-732.

Stepanichev, M.Y., Moiseeva, Y.V., Lazareva, N.A., Onufriev, M.V., Gulyaeva, N.V., 2003. Single intracerebroventricular administration of amyloid-beta (25-35) peptide induces impairment in short-term rather than long-term memory in rats. Brain Res. Bull. 61, 197-205.

Steriade, M., 2004. Acetylcholine systems and rhythmic activities during the waking-sleep cycle. Prog. Brain Res. 145, 179-196.

Steullet, P., Cabungcal, J.H., Kulak, A., Kraftsik, R., Chen, Y., Dalton, T.P., Cuenod, M., Do, K.Q., 2010. Redox dysregulation affects the ventral but not dorsal hippocampus: impairment of parvalbumin neurons, gamma oscillations, and related behaviors. J. Neurosci. 30, 2547-2558.

Storm, H.H., Jørgensen, H.O., Kejs, A.M.T., Engholm, G., 2006. Depleted uranium and cancer in Danish Balkan veterans deployed 1992-2001. Eur. J. Cancer 42, 2355 2358.

Sussulini, A., Becker, J.S., 2015. Application of laser microdissection ICP-MS for high resolution elemental mapping in mouse brain tissue: a comparative study with laser ablation ICP-MS. Talanta 132, 579-582.

Tallon-Baudry, C., Bertrand, O., Peronnet, F., Pernier, J., 1998. Induced gamma-band activity during the delay of a visual short-term memory task in humans. J. Neurosci. 18, 4244-4254.

Tchounwou, P.B., Yedjou, C.G., Patlolla, A.K., Sutton, D.J., 2012. Heavy metal toxicity and the environment. EXS 101, 133-164. 
Tomsig, J.L., Suszkiw, J.B., 1996. Metal selectivity of exocytosis in alpha-toxinpermeabilized bovine chromaffin cells. J. Neurochem. 66, 644-650.

Tournier, B.B., Frelon, S., Tourlonias, E., Agez, L., Delissen, O., Dublineau, I., Paquet, F., Petitot, F., 2009. Role of the olfactory receptor neurons in the direct transport of inhaled uranium to the rat brain. Toxicol. Lett. 190, 66-73.

Vacquier, B., Rage, E., Leuraud, K., Caër-Lorho, S., Houot, J., Acker, A., Laurier, D., 2011. The influence of multiple types of occupational exposure to radon, gamma rays and long-lived radionuclides on mortality risk in the French post-55 sub-cohort of uranium miners: 1956-1999. Rad. Res. 176, 796-806.

Vietti, K.R., Lasley, S.M., 2007. Stimulus-evoked glutamate release is diminished by acute exposure to uranium in vitro. Neurotoxicol. Teratol. 29, 607-612.

Yazzie, M., Gamble, S.L., Civitello, E.R., Stearns, D.M., 2003. Uranyl acetate cause DNA single strand breaks in vitro in the presence of ascorbate (vitamin C).

Chem. Res. Toxicol. 16, 524-530. 